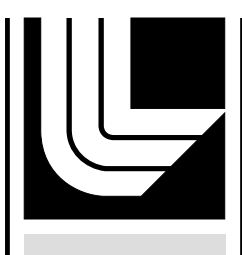

LAW RENCE LIVERMORE N A T IO N A L LABORATORY

\title{
NRL FTF 0.5MJ-Class Nominal Baseline Target
}

K. N. LaFortune, L. J. Perkins

December 17, 2007 
This document was prepared as an account of work sponsored by an agency of the United States government. Neither the United States government nor Lawrence Livermore National Security, LLC, nor any of their employees makes any warranty, expressed or implied, or assumes any legal liability or responsibility for the accuracy, completeness, or usefulness of any information, apparatus, product, or process disclosed, or represents that its use would not infringe privately owned rights. Reference herein to any specific commercial product, process, or service by trade name, trademark, manufacturer, or otherwise does not necessarily constitute or imply its endorsement, recommendation, or favoring by the United States government or Lawrence Livermore National Security, LLC. The views and opinions of authors expressed herein do not necessarily state or reflect those of the United States government or Lawrence Livermore National Security, LLC, and shall not be used for advertising or product endorsement purposes.

This work performed under the auspices of the U.S. Department of Energy by Lawrence Livermore National Laboratory under Contract DE-AC52-07NA27344. 


\title{
NRL FTF 0.5MJ-Class Nominal Baseline Target
} Hydra 1D/2D Results - Dec. 10, 2007

\author{
Kai N. LaFortune, L. John Perkins \\ (in collaboration with Andy Schmitt from NRL)
}

\section{Summary:}

This memo summarizes the latest progress in work on NRL 0.5 MJ-class FTF target. Since the last discussion, 1D performance issues have been resolved. The 1D performance issues inadvertently resulted from an effort to carefully compare the Lasnex and Hydra target simulations. The work has been expanded to 2D simulations of linear, single-1-mode growth simulations. The 2D simulations of mode growth in the linear regime indicate the target has a peak mode growth of around $1500 \mathrm{x}$ occurring near $\mathrm{l}=125$.

\section{$1 D$ performance summary:}

In the fall of '06, the two LLNL simulations disagreed modestly in performance: the Hydra simulations giving anomalously higher yields than Lasnex or even the FAST simulations. The input decks for both simulations were carefully reviewed. In the process of doing so, the simulations were stripped of complexities that may have introduced differences in target performance due to subtleties in the differences in which the physics was implemented in the two models. This included changing the EOS model from an older QEOS model to a more relevant, less-compressible, tabular LEOS model (see previous memo for details). It also included changing several input parameters and simplifying the radiation transport binning. In the spring of ' 07 , the LLNL team had targets that did not burn unless the drive energy was dramatically increased $(>60 \%)$. Initially, this increase was erroneously attributed to the newer, less-compressible EOS model. Subsequent perusal of the older, working decks and comparison with the recent decks revealed that the final state of the radiation transport model was oversimplified. The initial models had the radiation spectrum divided up into 90 bins. In intermediate cases the radiation transport was turned off completely. When the radiation transport was turned back on, one bin was used (i.e., the radiation spectrum was assumed to be Planckian). This is why the target simulations stopped working. The multi-group radiation diffusion model has been re-implemented; although, 90 bins are more than are needed to accurately keep track of the radiation diffusion.

\section{Target specs:}

\section{Initial temp: 1e-6 keV}

\begin{tabular}{lllll}
\multicolumn{2}{l}{ Initial geometry: } & & & \\
Region & At. fracts & Density(g/cc) & Radius (cm) & Thickness \\
DT gas & $1: 1$ & $2 \mathrm{e}-4$ & 0.0852 & 0.0852 \\
DT fuel & $1: 1$ & 0.2564 & 0.1058 & 0.0206 \\
CHDT Abl & $1: 1: 5.94: 5.94$ & $0.3312(100 \mathrm{mg} / \mathrm{cc}$ foam) & 0.1189 & 0.0131 \\
CH shell & $1: 1$ & 1.070 & 0.1194 & 0.0005
\end{tabular}


We employ a foam ablator density of $100 \mathrm{mg} / \mathrm{cc}$ (GA recommended minimum density for practical fabrication); a $40 \mathrm{mg} / \mathrm{cc}$ foam ablator similar to that of NRL was also run but the results will not be discussed here except to mention that there were no surprises in the performance. The only other small difference was DT ice density of 0.2564 vs. 0.2500 .

\section{EOS model:}

For the DT gas and ice layers the EOS of choice was the LEOS table \#1018 (same as NIF), which is the one benchmarked to Sandia and Russian data (see March '07 memo for references). It is less compressible than original QEOS model used. This is not the cause, as previously thought, of the decrease in the robustness of the $0.5 \mathrm{MJ}$ target simulations. The choice of EOS for the ablator layer was less obvious. Hydra currently does not support mixing tabular LEOSes within a region. And, there is no LEOS table for $100 \mathrm{mg} / \mathrm{cc}$ or $40 \mathrm{mg} / \mathrm{cc}$ wicked DT CH foam. Therefore, the choices are to stick with the older QEOS model that we know to be somewhat more compressible or to use the LEOS table for DT in the ablator. For the results in this memo, we have chosen to use the older QEOS model.

\section{Critical Hydra Parameters:}

Over the course of the past year, an effort was made to minimize discrepancies between Hydra and the other models (LASNEX \& FAST) not just in the geometry of the source and target but also in the various parameters passed to the models. A careful audit of the parameters used uncovered some discrepancies. Below is a list of critical parameters that were discussed and their latest values in the Hydra simulations.

$\begin{array}{lll}\begin{array}{l}\text { Parameter } \\ \text { rflxm }\end{array} & \begin{array}{l}\text { Value } \\ 1 . \mathrm{e} 20\end{array} & \begin{array}{l}\text { Comment } \\ \text { Radiation flux limiter: equivalent to Perkins' value of } 0 . \\ \text { This value essentially turns off radiation flux limiter; a } \\ \text { setting of 0 would inhibit all radiation flux }\end{array} \\ \text { eflxm } & 1.272 / .10 & \begin{array}{l}\text { Electron flux limiter: equivalent to NRL's value for the } \\ \text { electron flux }\end{array} \\ \begin{array}{l}\text { iflaser } \\ \text { rncrs }\end{array} & \begin{array}{l}\text { Spherical source (purely radial rays) } \\ \text { (for all regions) }\end{array} & \begin{array}{l}\text { Regional neutron scattering cross section } \\ \end{array}\end{array}$

\section{D results:}

With the proper parameters, EOS model and radiation transport granularity, it was easy to achieve target performance similar to that achieved in the NRL point design. The laser pulse shape, after shock timing, appears in Figure 1. Note: we are still using a spherically-symmetric source, so all rays are radially-incident, there is no laser imprint (for 2D) and there is no "zooming" of the focal spot. 


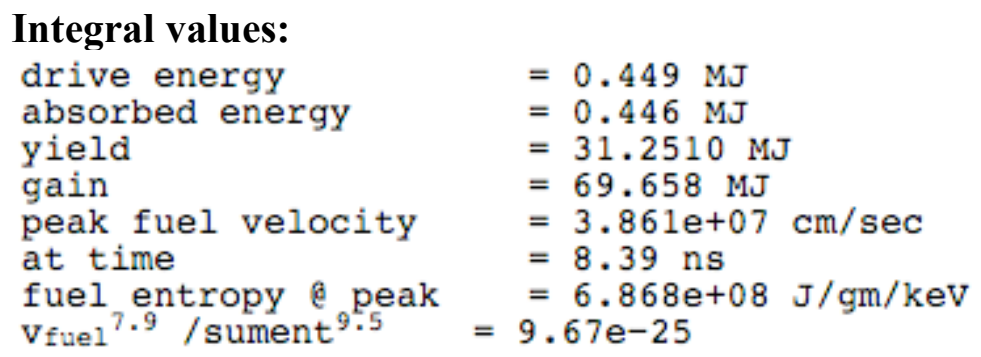

The data presented in this memo continued to use 90 bin multi-group radiation diffusion. But, much effort has gone into optimizing the radiation transport binning granularity for simulation run time. At 90 bins, $90 \%$ of the computational cost is in the radiation transport. Figure 5 illustrates the relationship between the material opacity and radiation spectrum (sampled with the full 90 bins). The goal, of course, is to minimize the number of bins without under-sampling the spectral features. Note the features near $0.3-0.4 \mathrm{eV}$.

\section{D performance:}

With the 1D target shock-timed, 2D simulations of perturbation growth were performed. 2D single mode linear stability analysis was performed by applying a small perturbation (1.0e-9cm amplitude) on outside of ablator, feathered to zero at the fuel-ablator interface. The 5 micron outer shell was conformally mapped onto the outside of the perturbation. The mode amplitude at both the ablation front and the fuel-ablator interface were tracked during these simulations. The simulations ran with low (numerical) noise as measured by comparing the mode shape at time $t$ to the shape at time zero (see examples in Figure 6 and 7 for $1=25$ and $1=125$, respectively).

The mode growth as measured by the ratio of the mode amplitude at peak kinetic energy to the amplitude at time zero, is plotted in Figure 8 as a function of 1 mode number. It peaks around $1=125$ after going through a sign reversal between $1=75 \& 1=100$. The mode amplitude is characterized three different ways: by the mesh perturbation at the ablation front and by the integral rho-R perturbation integrated out to the ablation front and also to the edge of the problem. The location of the ablation front is defined to be the mesh node for which the gradient in density is a maximum. In the figures in the appendix of the time-dependence of the perturbations, the blue curve is the integral up to the ablation front and the cyan curve is the integral over the whole problem. The integral rho-R perturbation up to the ablation front goes through a phase shift but that over the whole problem does not. There does not seem to be a strong dependence on the choice of upper limit of integration. The amplitude of the perturbation measured at intermediate positions goes through a smooth transition from one value to the other. 


\section{Appendix (Figures):}

(see accompanying documents for additional figures - e.g., plasma radial profiles versus times and a set of time dependent growths for each 1-mode)

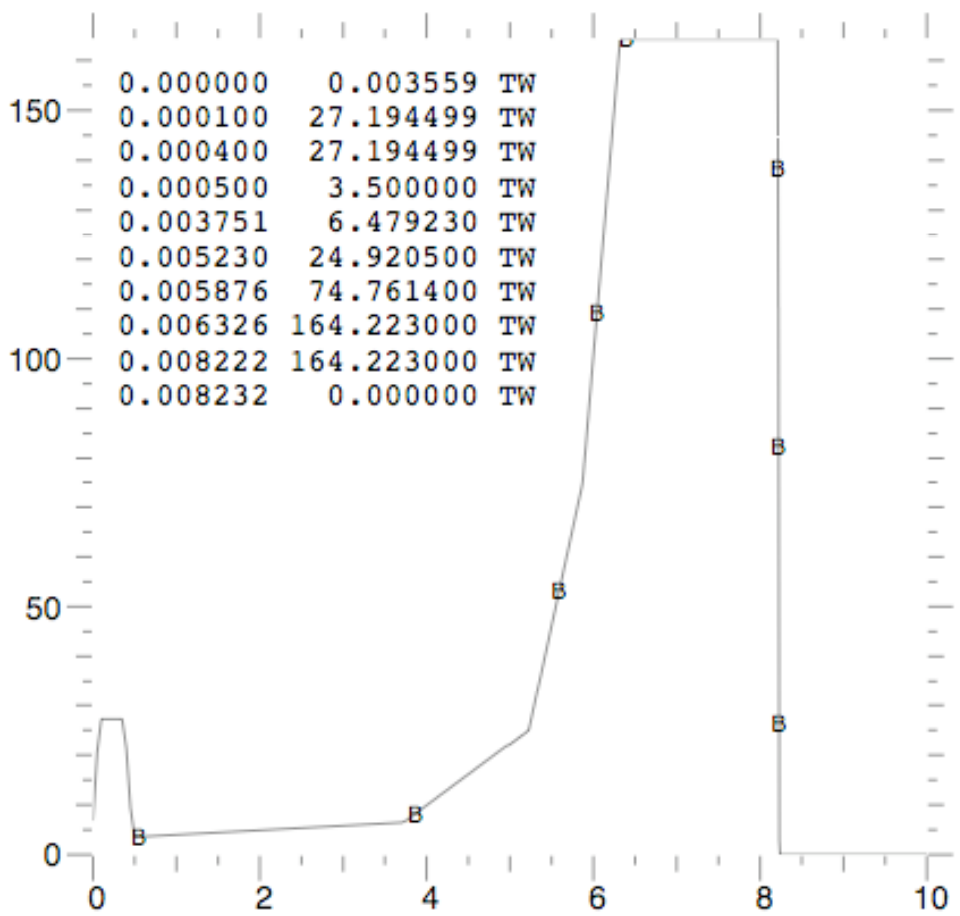

Figure 1: Laser power (in TeraWatts) as a function of time (in nanoseconds) after shock timing.

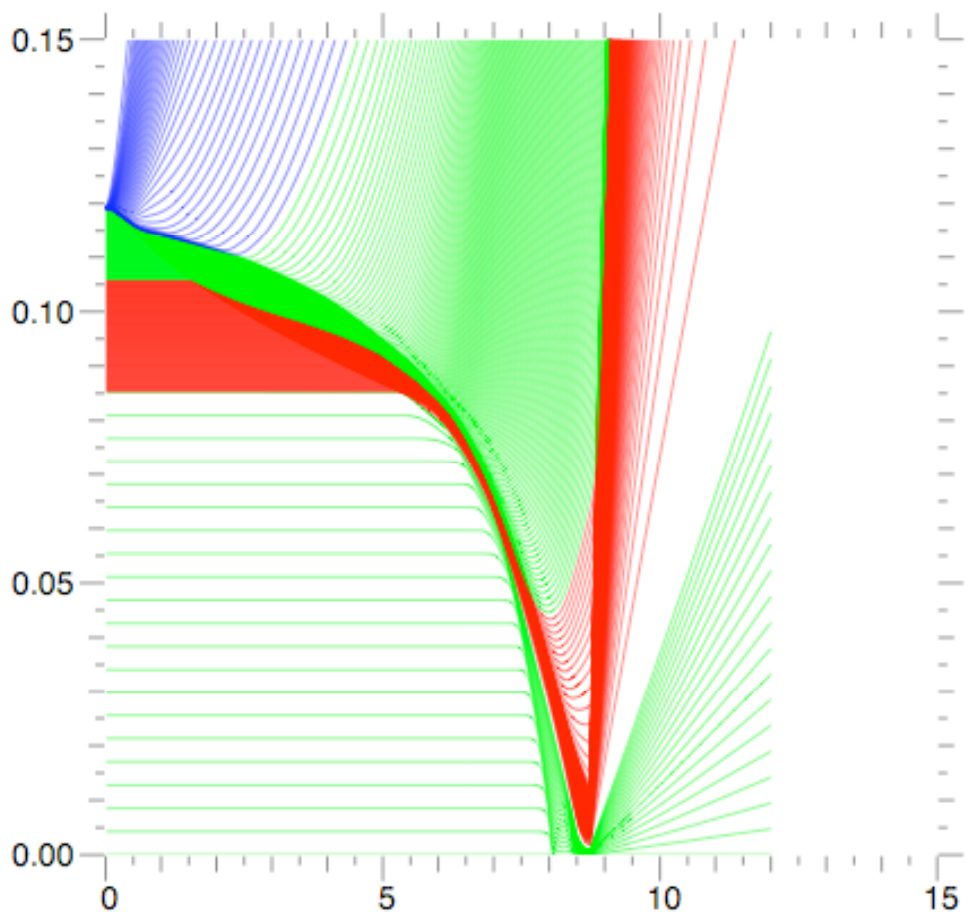

Figure 2: 1D target geometry $(\mathrm{cm})$ as a function of time $(\mathrm{ns})$. yellow $=$ DT gas, red $=$ DT fuel, green $=$ CHDT ablator, blue $=\mathrm{CH}$ shell 


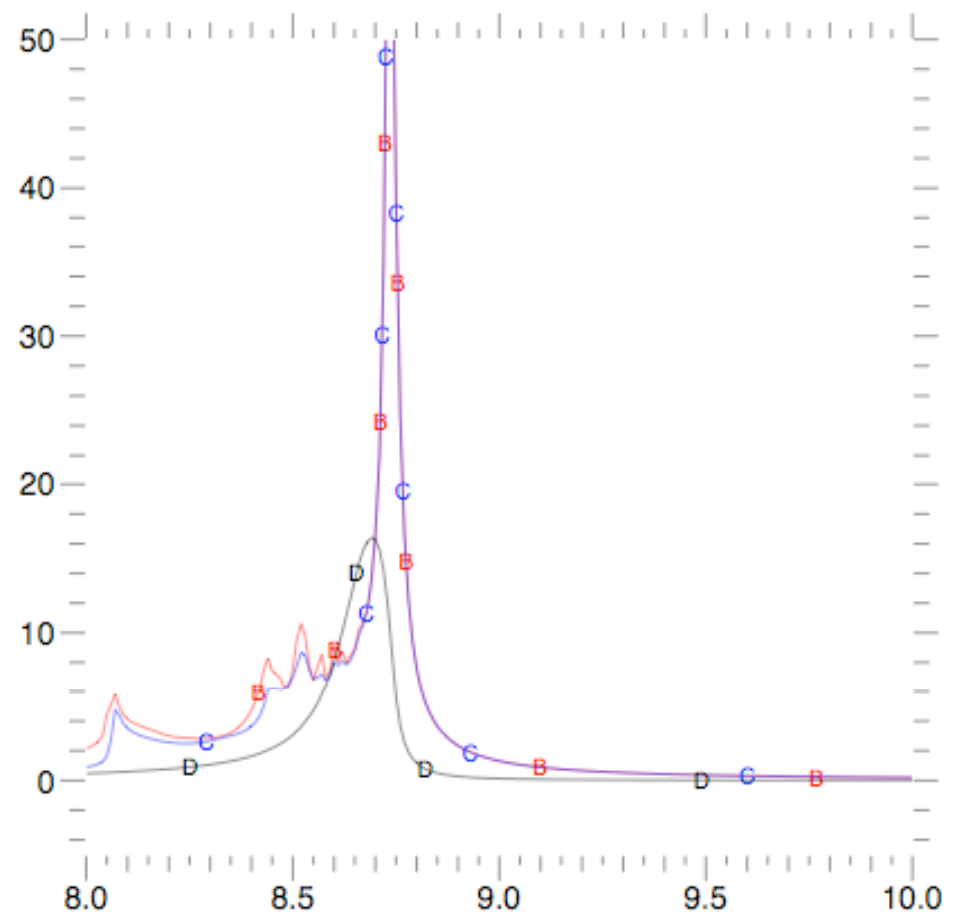

Figure 3: In keV, on-axis ion temp (B) the density-weighted ion temp (C) and the integral rho-R x10 (D), as functions of time (ns). Max rho- $\mathrm{R}=1.64$ at $8.7 \mathrm{~ns}$ and $\max$ ion temp $=63 \mathrm{keV}$.

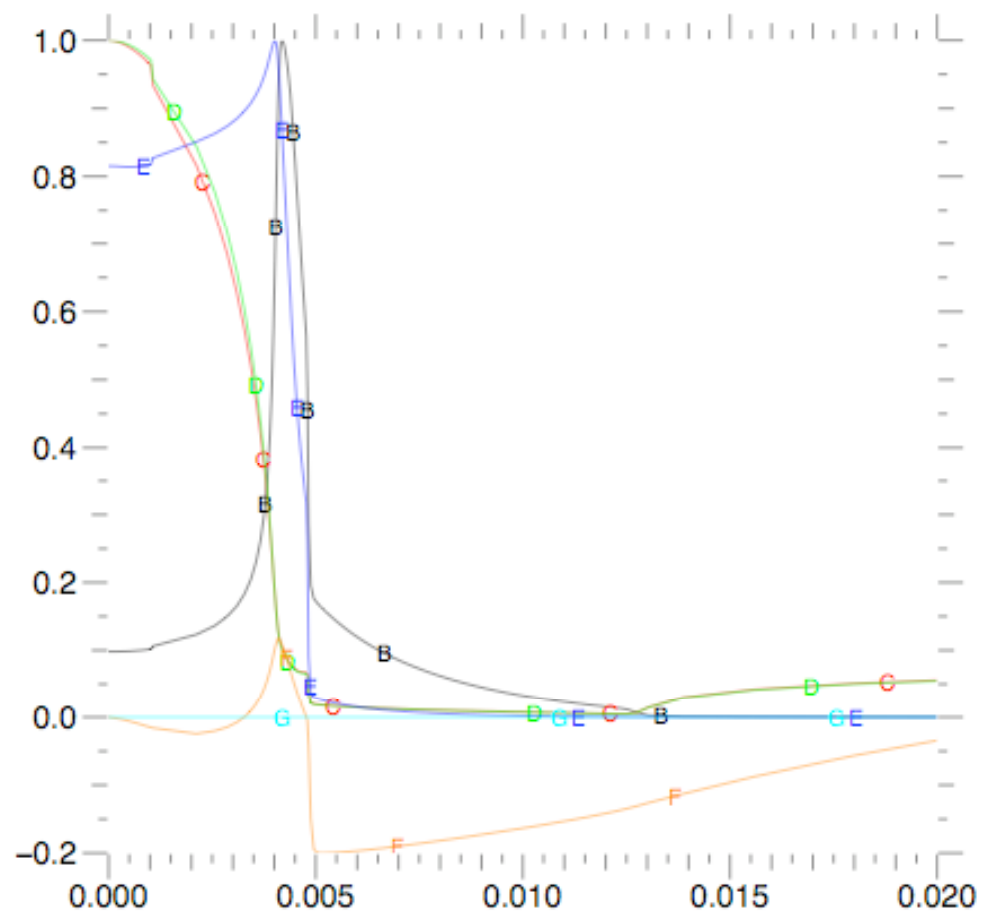

Figure 4 Radial slice at ignition of normalized density (B), ion temp (C), electron temp (D), pressure (E), velocity (F) and integral laser deposition (G) (see accompanying document for details and radial slices at other times). 


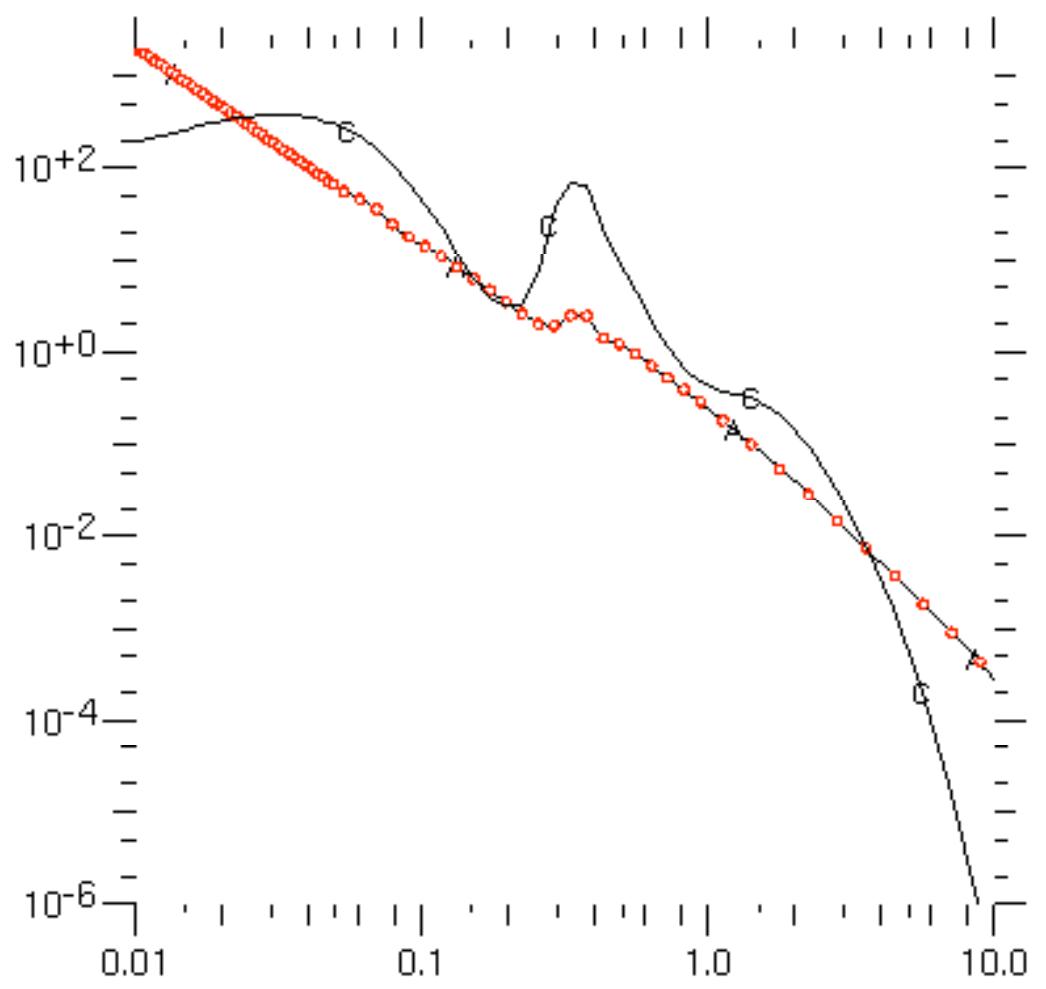

Figure 5: Opacity of DT in target (A, red dot) and radiation density (C) as a function of energy (in keV).

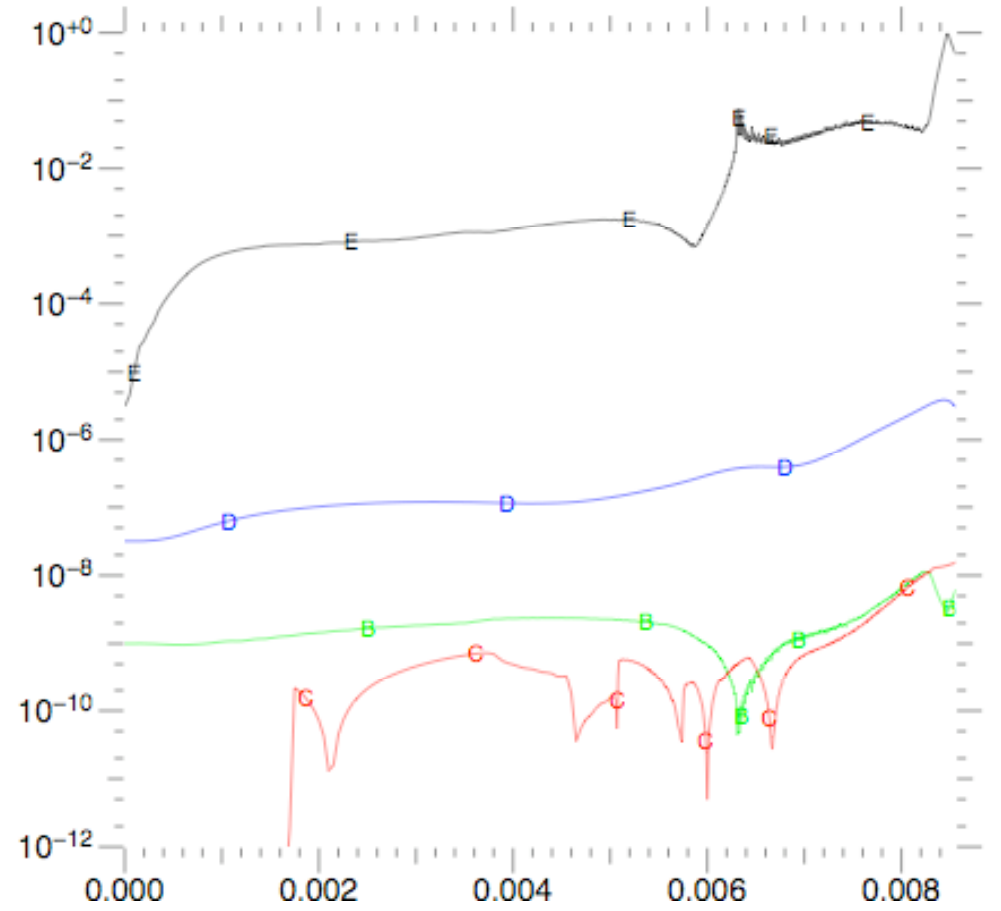

Figure 61 mode $=25$, the peak-to-valley mode aplitude in $\mathrm{cm}$ at the ablation front (B) and fuel-ablator interface (C) and the rho-R perturbation (D) as a function of time (in microseconds). Also plotted is the chi-square fit of the mode at the ablation front. 


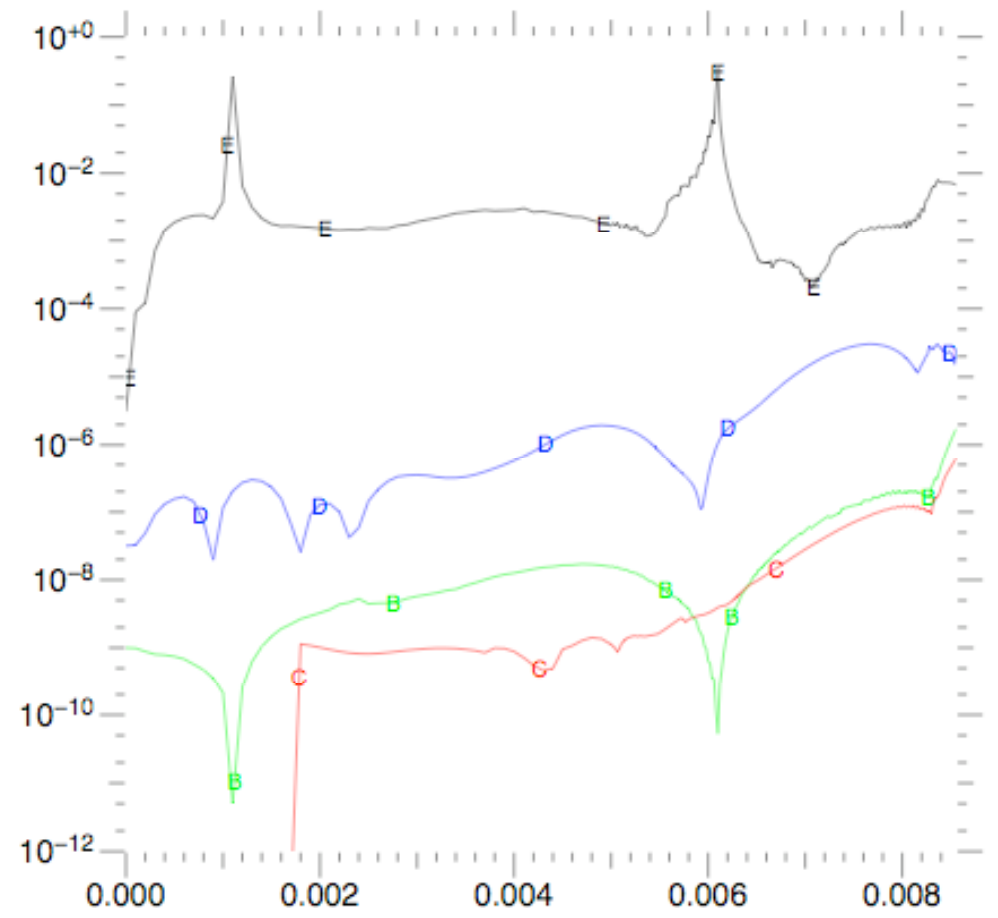

Figure 7: 1 mode $=125$, the peak-to-valley mode amplitude in $\mathrm{cm}$ at the ablation front (B) and fuel-ablator interface (C) and the rho-R perturbation (D) as a function of time (in microseconds). Also plotted is the chi-square fit of the mode at the ablation front (E). See accompanying document for figures for other mode numbers.

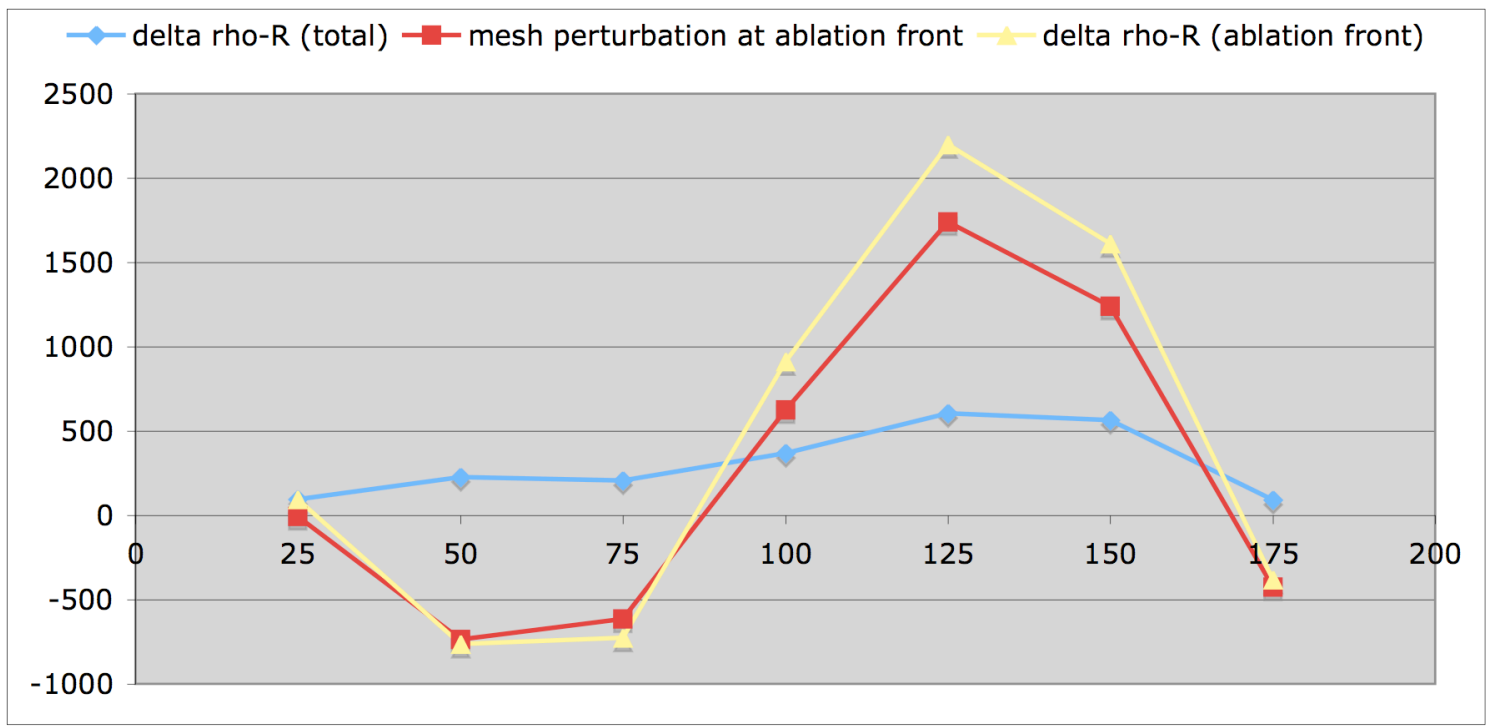

Figure 8: Mode growth factor as a ratio of the amplitude of the mesh perturbation at peak velocity to its amplitude at $\mathrm{t}=0 \mathrm{~ns}$ (red). Note: negative mode growth corresponds to a net phase change. Growth factors of the amplitude of the integral rho-R perturbation with the upper limit of the integral at the ablation front (yellow) and at the edge of the problem (blue). 
filename $=\mathrm{gftf}$

creation date $=2007-10-0912: 16: 33$

print date = Thu Dec 13 13:56:08 2007

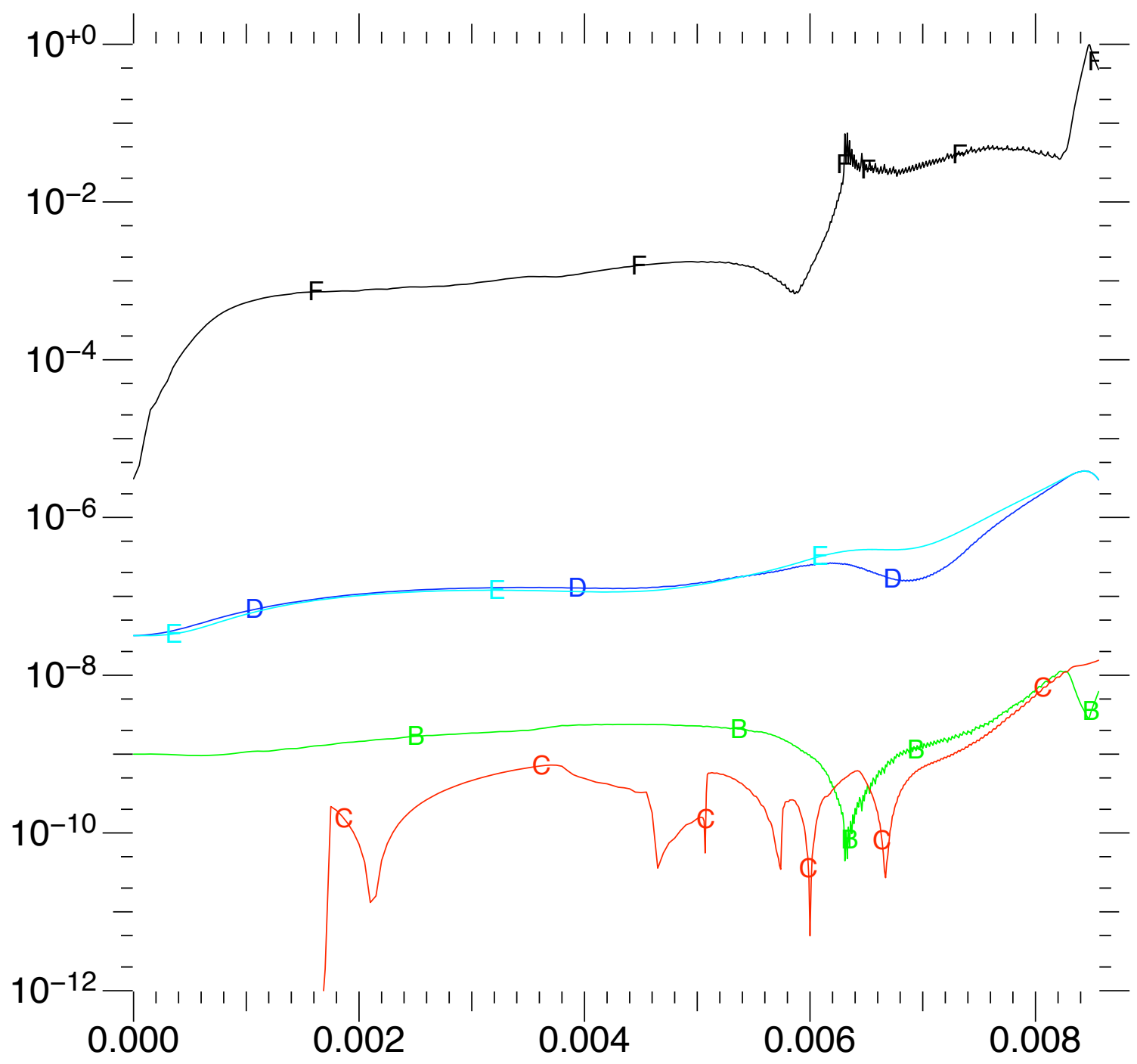

B: plg, abs (mode_amplitude), $t$

C: plg, fa_amplitude, $t$

D: plg, rho_r_amplitude, $t$

E: plg, rho_r_total_amplitude, $t$

F: plg, chi_squared_fit, $t$

time of $\max \mathrm{KE}=0.00856002$

$\begin{array}{ll}\text { last time step at } & 0.00892000 \text { microseconds } \\ \text { mode number } & 25\end{array}$

mode growth factor $=\quad-6.22 e+00$

rho- $\mathrm{R}$ growth factor $=9.38 \mathrm{e}+01$ 
filename $=$ oftf

creation date $=2007-10-2311: 36: 57$

print date = Thu Dec 13 13:56:14 2007

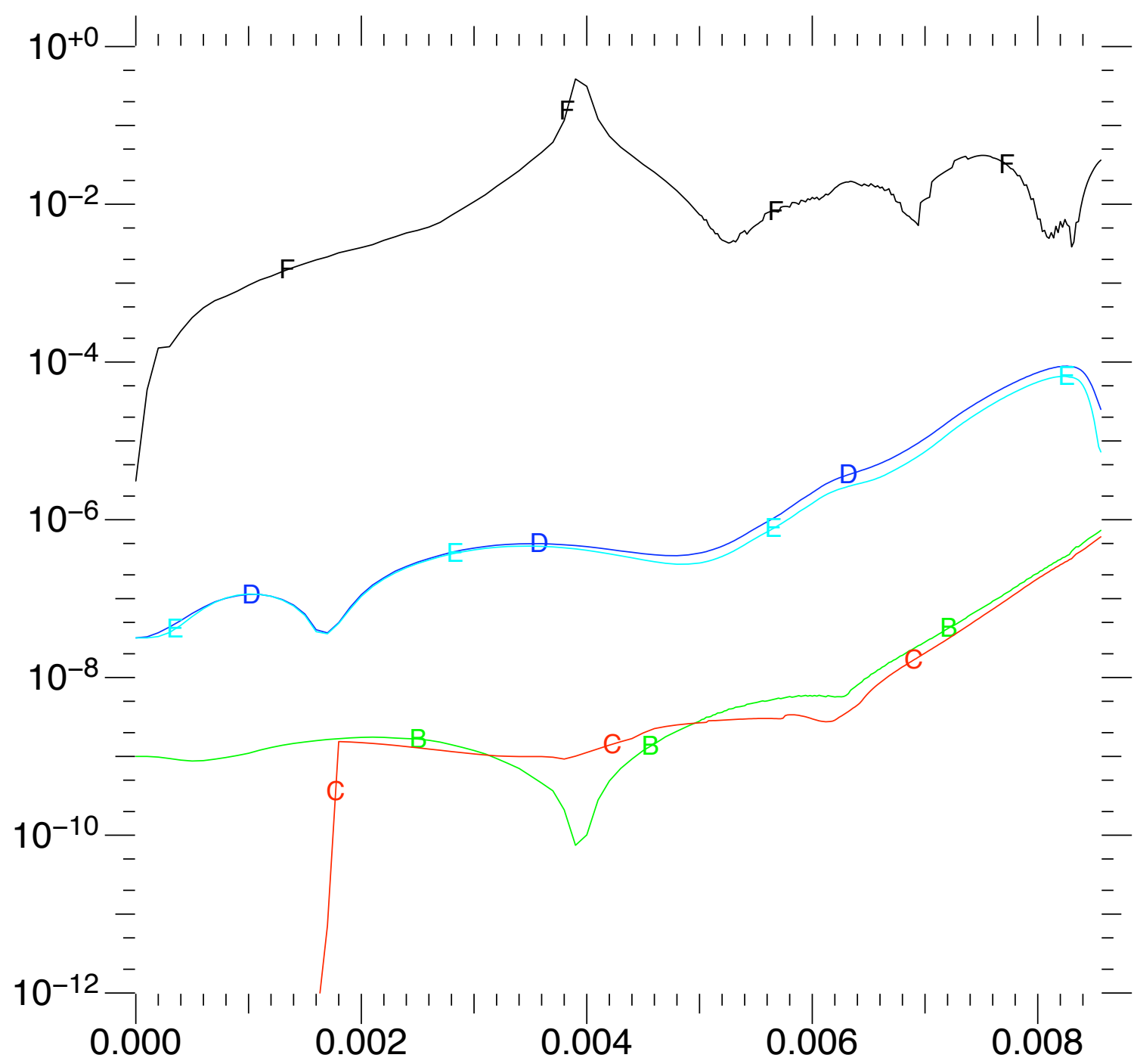

B: plg, abs (mode_amplitude), $t$

C: plg, fa_amplitude, $t$

D: plg, rho_r_amplitude, $t$

E: plg, rho_r_total_amplitude, $t$

F: plg, chi_squared_fit, $t$

time of $\max \mathrm{KE}=0.00856001$

last time step at $\quad 0.00896000$ microseconds

mode number $=50$

mode growth factor $=\quad-7.35 e+02$

rho- $\mathrm{R}$ growth factor $=\quad-7.62 \mathrm{e}+02$ 
filename $=\mathrm{mftf}$

creation date $=2007-10-18$ 15:54:18

print date $=$ Thu Dec 13 13:56:37 2007

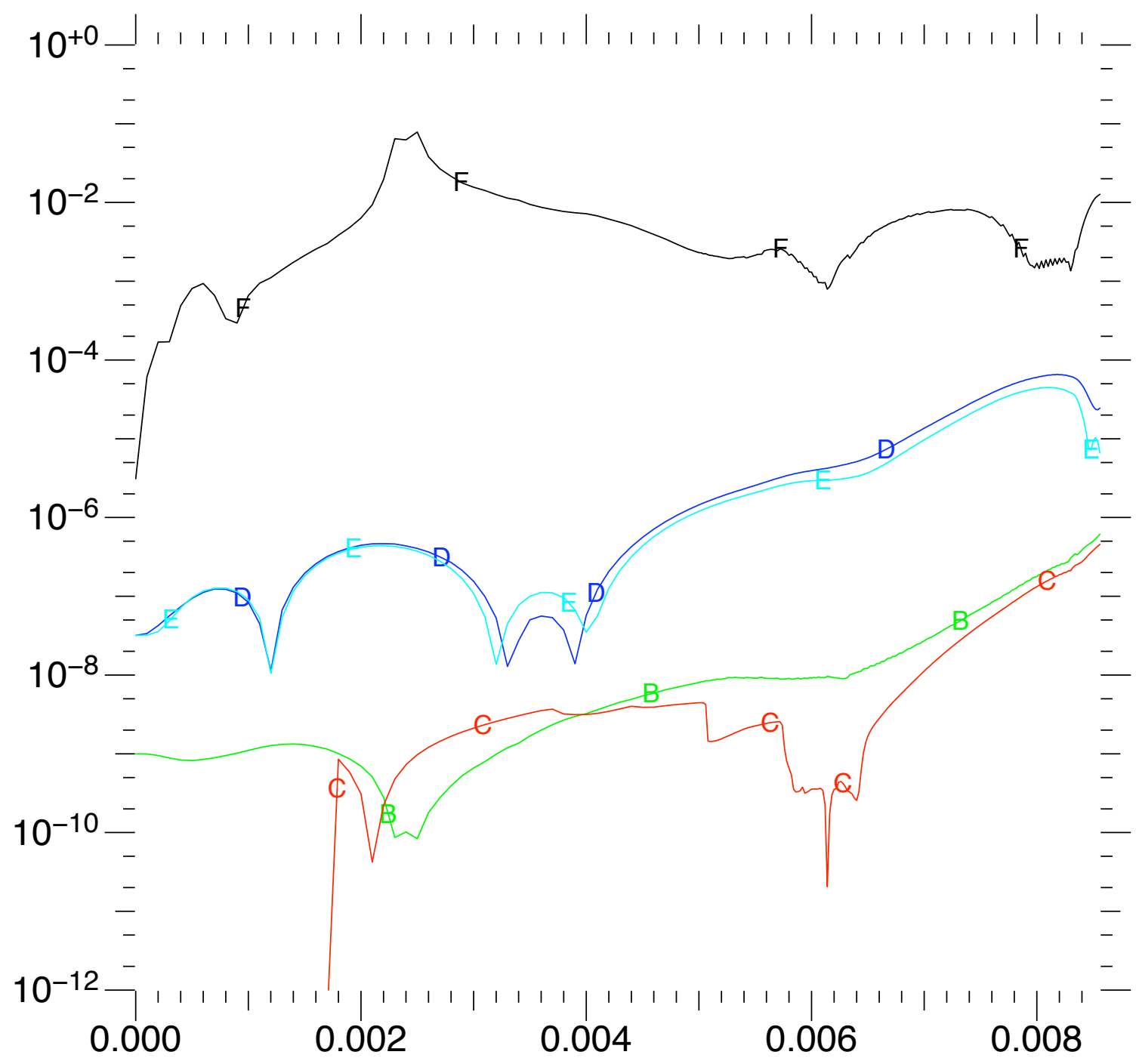

B: plg, abs(mode amplitude), $t$

C: plg, fa_amplitude, $t$

D: plg, rho_r_amplitude, $t$

E: plg, rho_r_total_amplitude, $t$

F: plg, chi_squared_fit, $t$

time of $\max \mathrm{KE}=0.00856001$
last time step at $\quad 0.00894000$ microseconds mode number $=75$

mode growth factor $=\quad-6.15 e+02$

rho- $\mathrm{R}$ growth factor $=\quad-7.28 \mathrm{e}+02$ 
filename $=\mathrm{lftf}$

creation date $=2007-10-14$ 14:12:53

print date $=$ Thu Dec 13 13:57:03 2007

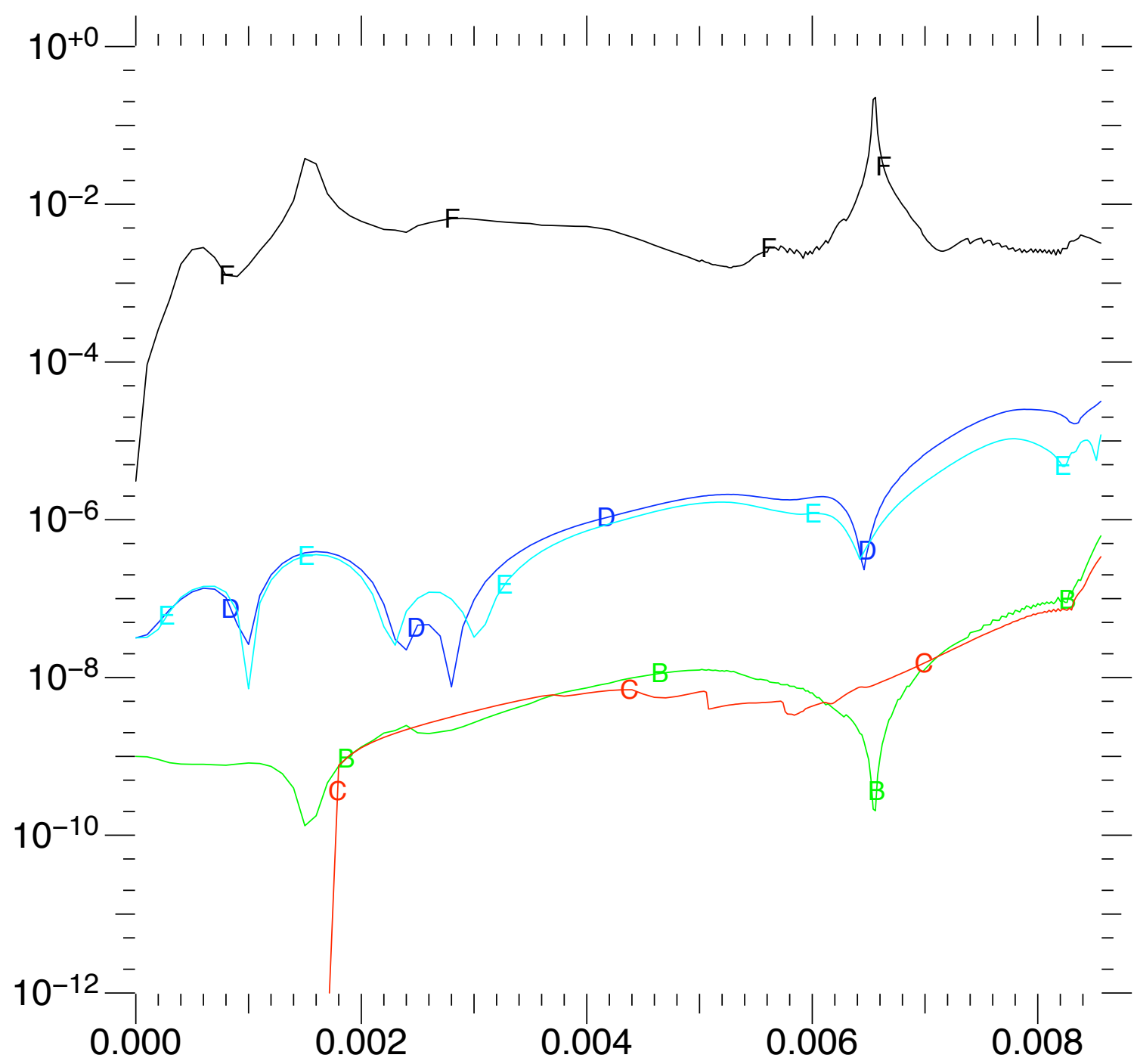

$B: p l g$, abs (mode_amplitude), $t$

C: plg, fa_amplitude, $t$

D: plg, rho_r_amplitude, $t$

E: plg, rho_r_total_amplitude, $t$

F: plg, chi_squared_fit, $t$

time of $\max \mathrm{KE}=0.00856001$

last time step at $\quad 0.00892000$ microseconds

mode number $=100$

mode growth factor $=6.25 e+02$

rho- $\mathrm{R}$ growth factor $=9.11 \mathrm{e}+02$ 
filename $=\mathrm{nftf}$

creation date $=2007-10-18$ 16:12:51

print date = Thu Dec 13 13:57:27 2007

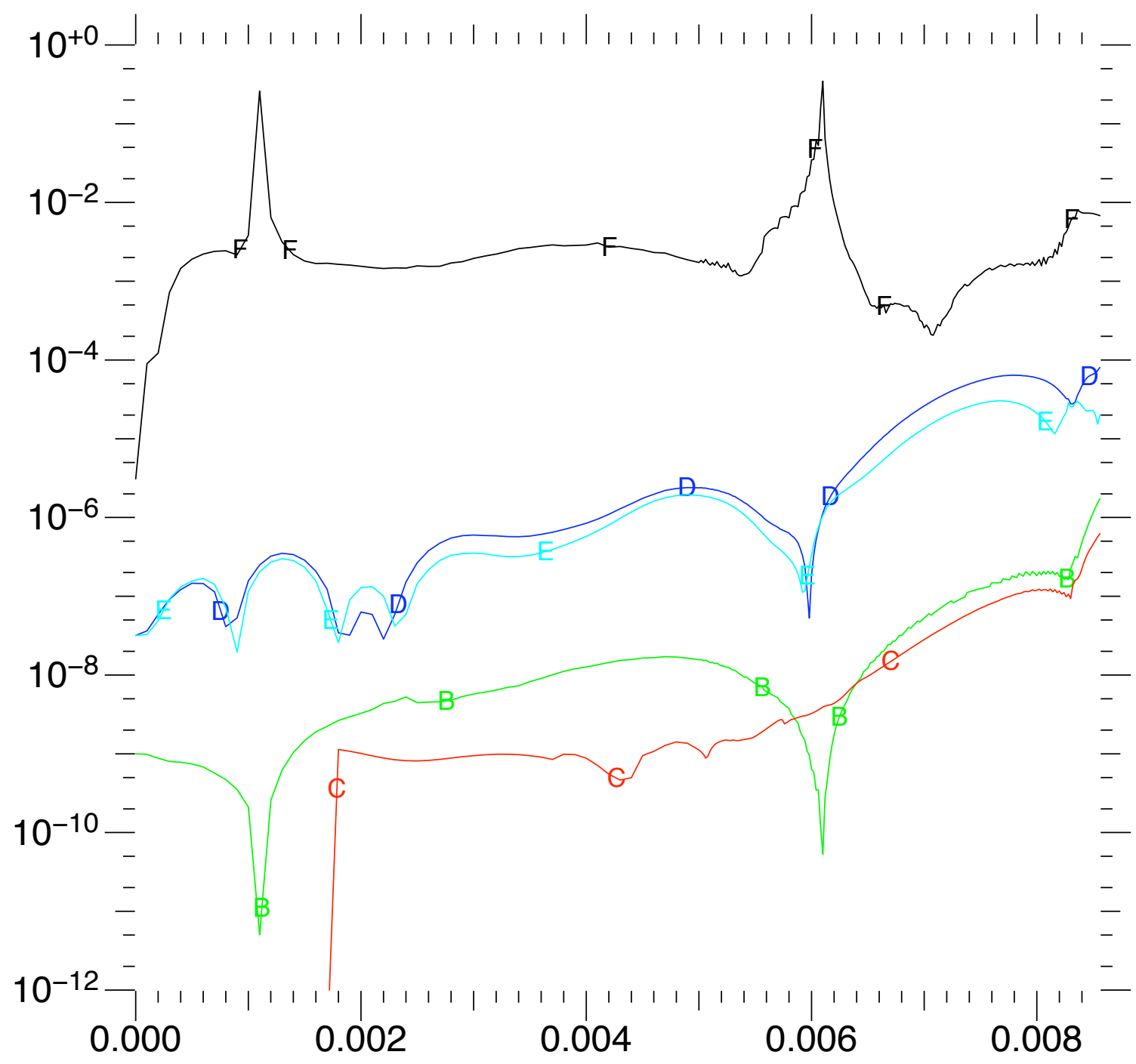

B: plg, abs (mode_amplitude), $t$

C: plg, fa_amplitude, $t$

D: plg, rho_r_amplitude, $t$

E: plg, rho_r_total_amplitude, $t$

F: plg, chi_squared_fit, $t$

time of $\max \mathrm{KE}=0.00856003$

last time step at $\quad 0.00886000$ microseconds

mode number $=125$

mode growth factor $=1.74 \mathrm{e}+03$

rho-R growth factor $=2.20 e+03$ 
filename $=$ pftf

creation date $=2007-10-2314: 13: 51$

print date $=$ Thu Dec 13 13:57:51 2007

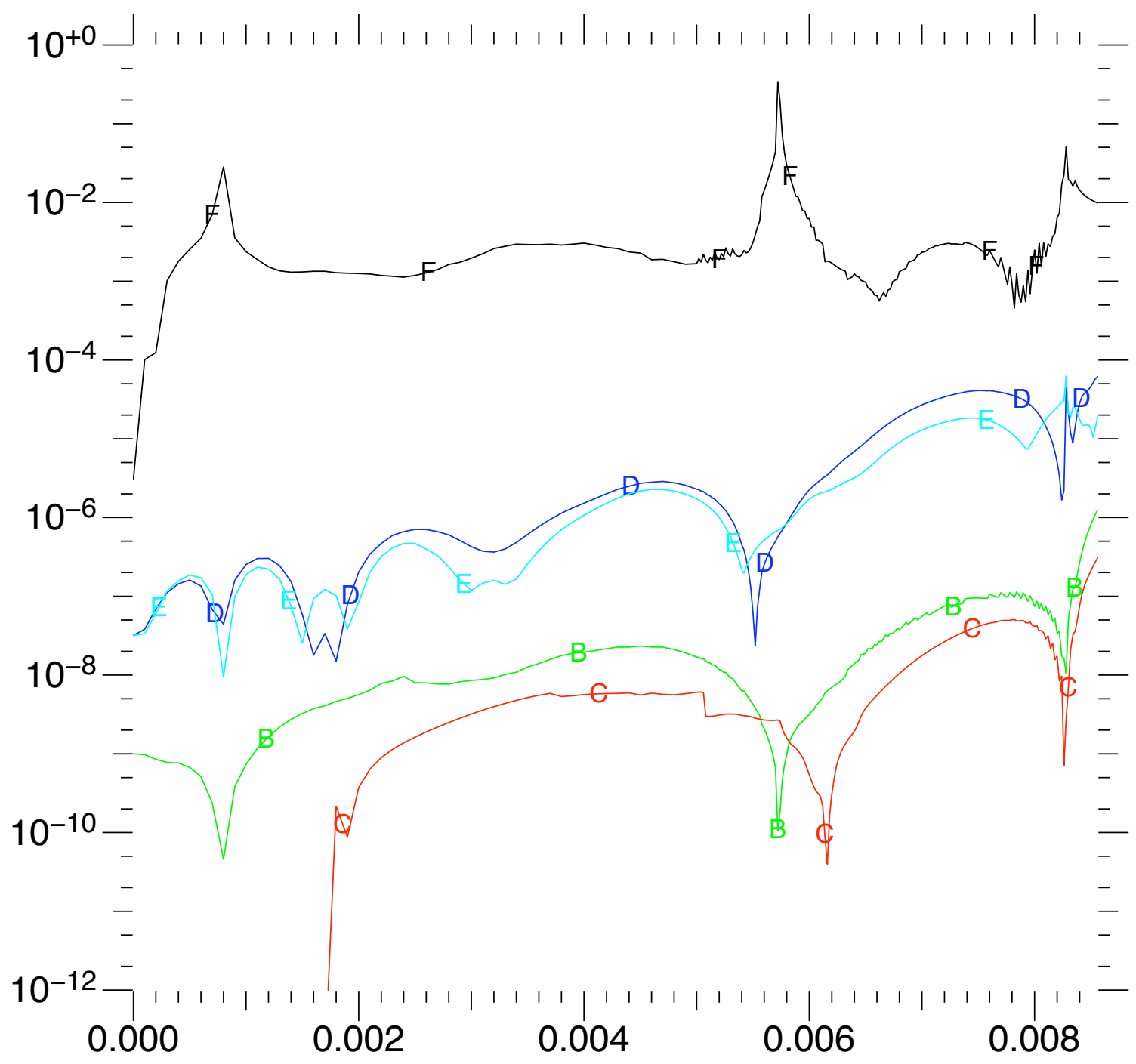

B: plg, abs (mode_amplitude), $t$

C: plg, fa_amplitude, $t$

D: plg, rho_r_amplitude, $t$

E: plg, rho_r_total_amplitude, $t$

F: plg, chi_squared_fit, $t$

time of $\max \mathrm{KE}=0.00856002$

last time step at $\quad 0.00886000$ microseconds

mode number $=150$

mode growth factor $=1.24 \mathrm{e}+03$

rho-R growth factor $=1.61 \mathrm{e}+03$ 
filename $=$ qftf

creation date $=2007-10-29$ 18:28:56

print date $=$ Thu Dec 13 13:58:15 2007

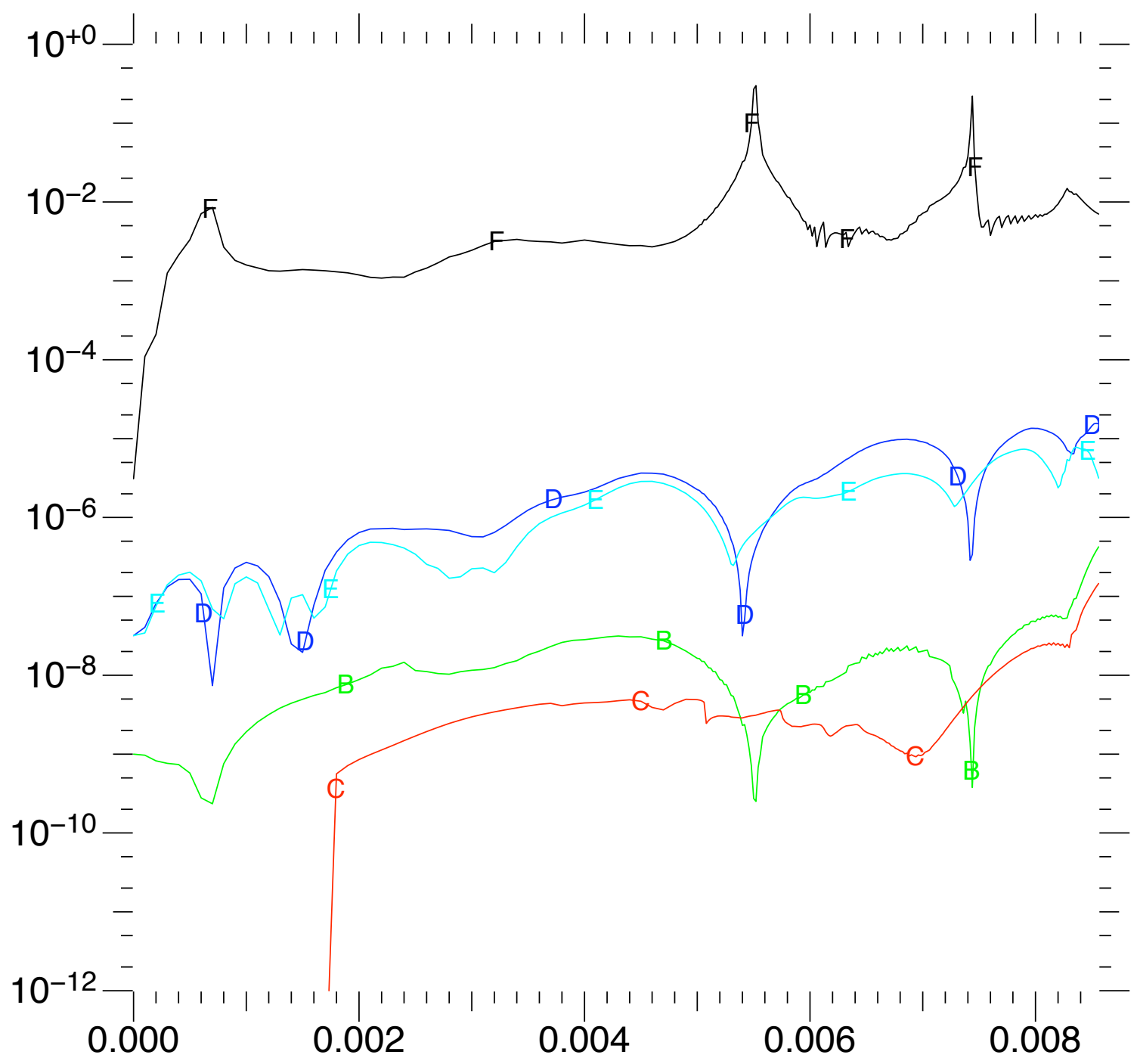

$B: p l g$, abs (mode_amplitude), $t$

C: plg, fa_amplitude, $t$

D: plg, rho_r_amplitude, $t$

E: plg, rho_r_total_amplitude, $t$

F: plg, chi_squared_fit, $t$

time of $\max \mathrm{KE}=0.00856002$

last time step at $\quad 0.00884000$ microseconds

mode number $=175$

mode growth factor $=\quad-4.24 e+02$

rho-R growth factor $=\quad-3.81 e+02$ 
filename $=\mathrm{ftst}$

creation date $=2007-10-1014: 26: 11$

print date $=$ Fri Dec 7 07:42:41 2007

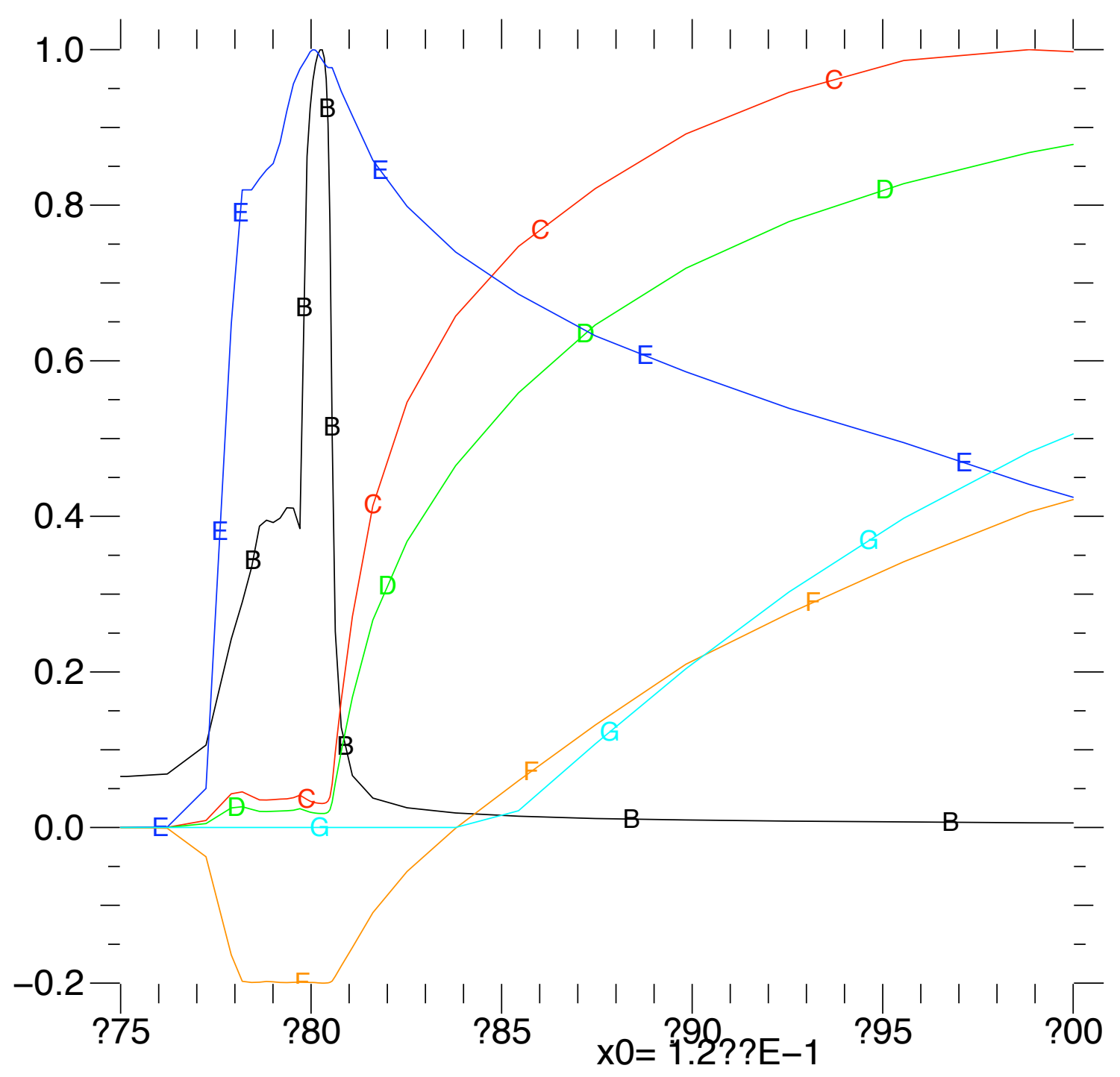

B: plg, density/max(density), $r$

C: plg, ion_temp/max(ion_temp), r

D: plg, electron_temp/max (electron_temp), r

E: plg, pressure/max(pressure), r

F: plg, $-0.2 *$ velocity/min(velocity), r

G: plg, integral_laser_deposition/max(integral_laser_deposition), r

radial slice at max density

$\max$ ion temp

max electron temp

max total pressure max inward velocity = total laser deposition

$\begin{array}{rr} & 0.250000 \text { nanoseconds } \\ = & 4.26179 \mathrm{~g} / \mathrm{cc} \\ = & 481.348 \mathrm{eV} \\ = & 826.913 \mathrm{eV} \\ = & 25.6320 \mathrm{Mb} \\ = & -7.66044 \mathrm{e}+06 \mathrm{~cm} / \mathrm{sec} \\ \text { n } & \text { per unit volume } * \mathrm{dV}=\end{array}$

0.250000 nanoseconds

$481.348 \mathrm{eV}$

$826.913 \mathrm{eV}$

$25.6320 \mathrm{Mb}$

$-7.66044 \mathrm{e}+06 \mathrm{~cm} / \mathrm{sec}$

$\mathrm{dV}=$ 
filename $=\mathrm{ftst}$

creation date $=2007-10-1014: 26: 11$

print date $=$ Fri Dec 7 07:43:56 2007

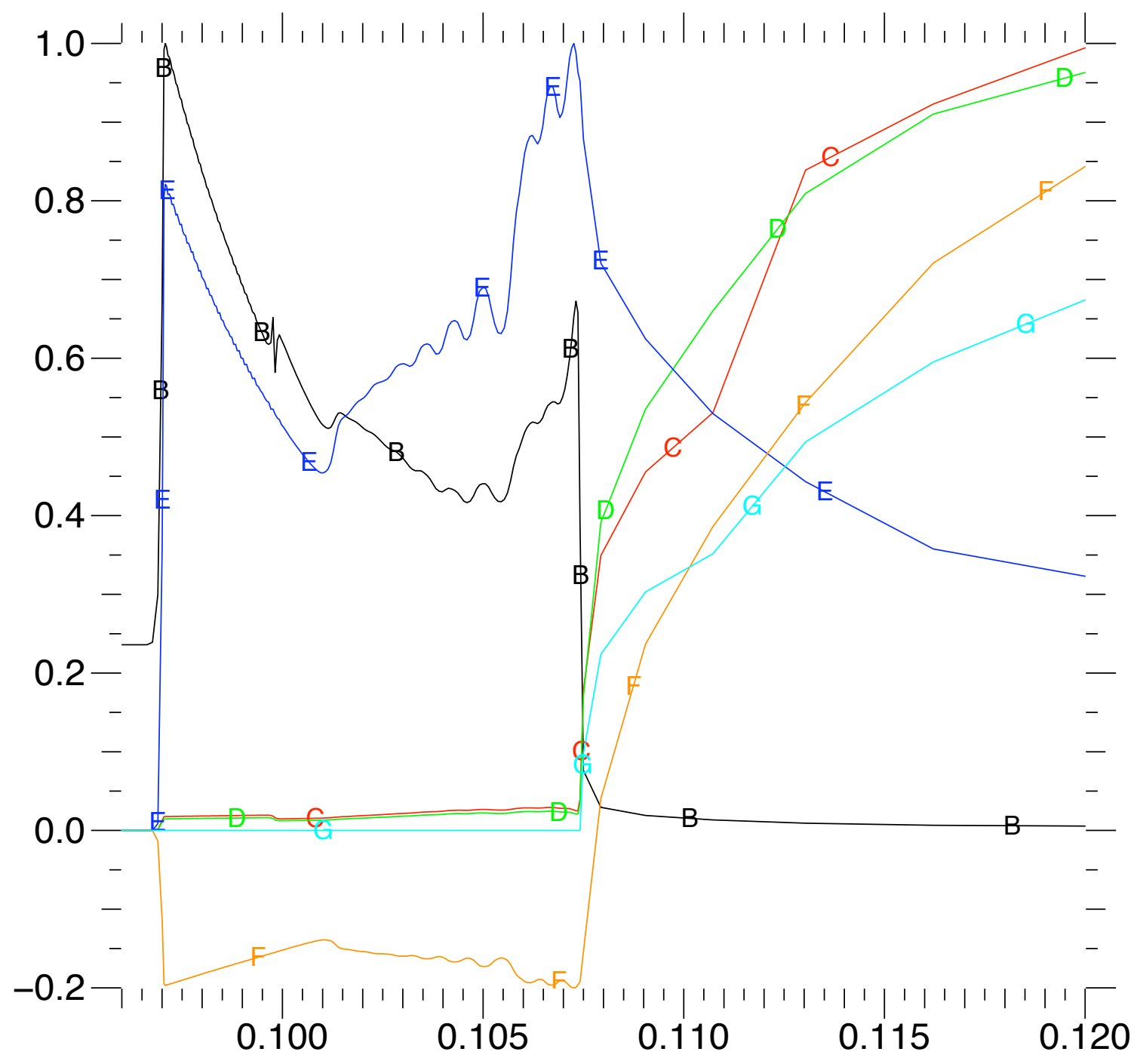

B: plg, density/max(density), $r$

C: plg, ion_temp/max(ion_temp), $r$

D: plg, electron_temp/max (electron_temp), r

$\mathrm{E}$ : plg, pressure $/ \max ($ pressure), $r$

F: plg, $-0.2 *$ velocity/min(velocity), $r$

G: plg, integral_laser_deposition/max(integral_laser_deposition), r

radial slice at max density

$\max$ ion temp

max electron temp

max total pressure

max inward velocity = total laser deposition

$\begin{array}{cr} & 3.00000 \text { nanoseconds } \\ = & 1.08656 \mathrm{~g} / \mathrm{CC} \\ = & 534.478 \mathrm{eV} \\ = & 639.698 \mathrm{eV} \\ = & 7.39039 \mathrm{Mb} \\ = & -4.33583 e+06 \mathrm{~cm} / \mathrm{sec} \\ \text { n } & \text { per unit volume } * \mathrm{dV}=\end{array}$


filename $=\mathrm{ftst}$

creation date $=2007-10-1014: 26: 11$

print date $=$ Fri Dec 7 07:45:35 2007

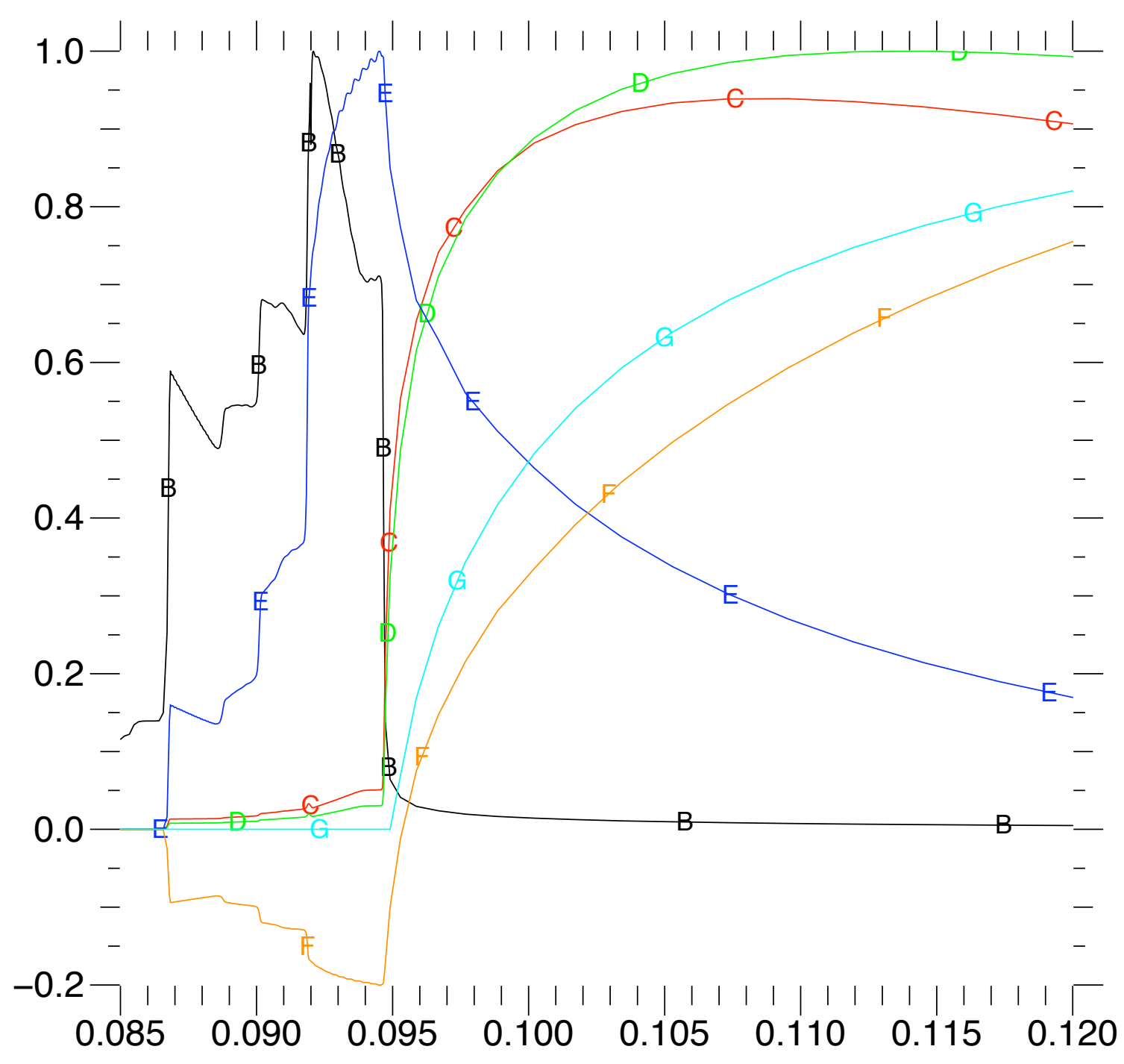

B: $p l g$, density/max(density), $r$

C: plg, ion_temp/max(ion_temp), r

D: plg, electron_temp/max (electron_temp), r

$\mathrm{E}$ : plg, pressure $\overline{\max }$ (pressure), r

F: plg, $-0.2 *$ velocity/min(velocity), r

G: plg, integral_laser_deposition/max(integral_laser_deposition), r

radial slice at max density

$\max$ ion temp

max electron temp

max total pressure =

$$
\begin{array}{llr}
\text { radial slice at } & & 5.00000 \text { nanoseconds } \\
\max \text { density } & = & 1.84051 \mathrm{~g} / \mathrm{cc} \\
\max \text { ion temp } & 536.782 \mathrm{eV} \\
\max \text { electron temp } & = & 896.189 \mathrm{eV} \\
\max \text { total pressure } & = & 27.8106 \mathrm{Mb} \\
\max \text { inward velocity } & = & -7.73655 \mathrm{e}+06 \mathrm{~cm} / \mathrm{sec}
\end{array}
$$$$
\text { total laser deposition per unit volume } * d V=
$$ 
filename $=\mathrm{ftst}$

creation date $=2007-10-1014: 26: 11$

print date $=$ Fri Dec 7 07:46:36 2007

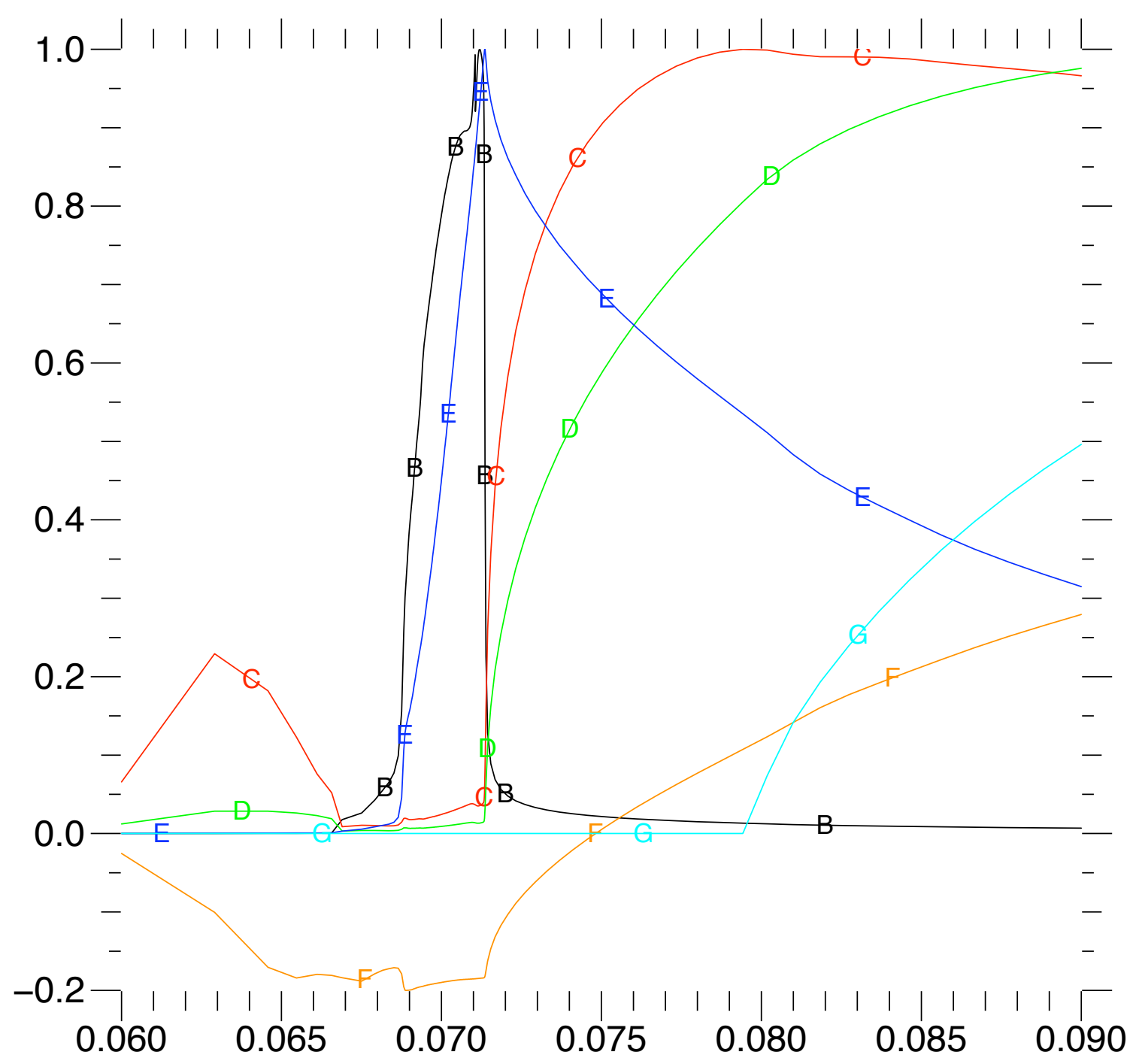

B: plg, density/max(density), $r$

C: plg, ion_temp/max(ion_temp), $r$

D: plg, electron_temp/max (electron_temp), r

E: plg, pressure/max(pressure), $r$

F: plg, $-0.2 *$ velocity/min(velocity), r

G: plg, integral_laser_deposition/max(integral_laser_deposition), r

radial slice at max density $\max$ ion temp

max electron temp max total pressure = max inward velocity = total laser deposition

$$
\begin{array}{cr} 
& 6.80000 \text { nanoseconds } \\
= & 5.86687 \mathrm{~g} / \mathrm{cC} \\
= & 971.216 \mathrm{eV} \\
= & 2596.03 \mathrm{eV} \\
= & -2.35617 \mathrm{e}+07 \mathrm{~cm} / \mathrm{sec} \\
\text { n } & \text { per unit volume } * \mathrm{dV}=
\end{array}
$$


filename $=\mathrm{ftst}$

creation date $=2007-10-1014: 26: 11$

print date $=$ Fri Dec 7 07:47:54 2007

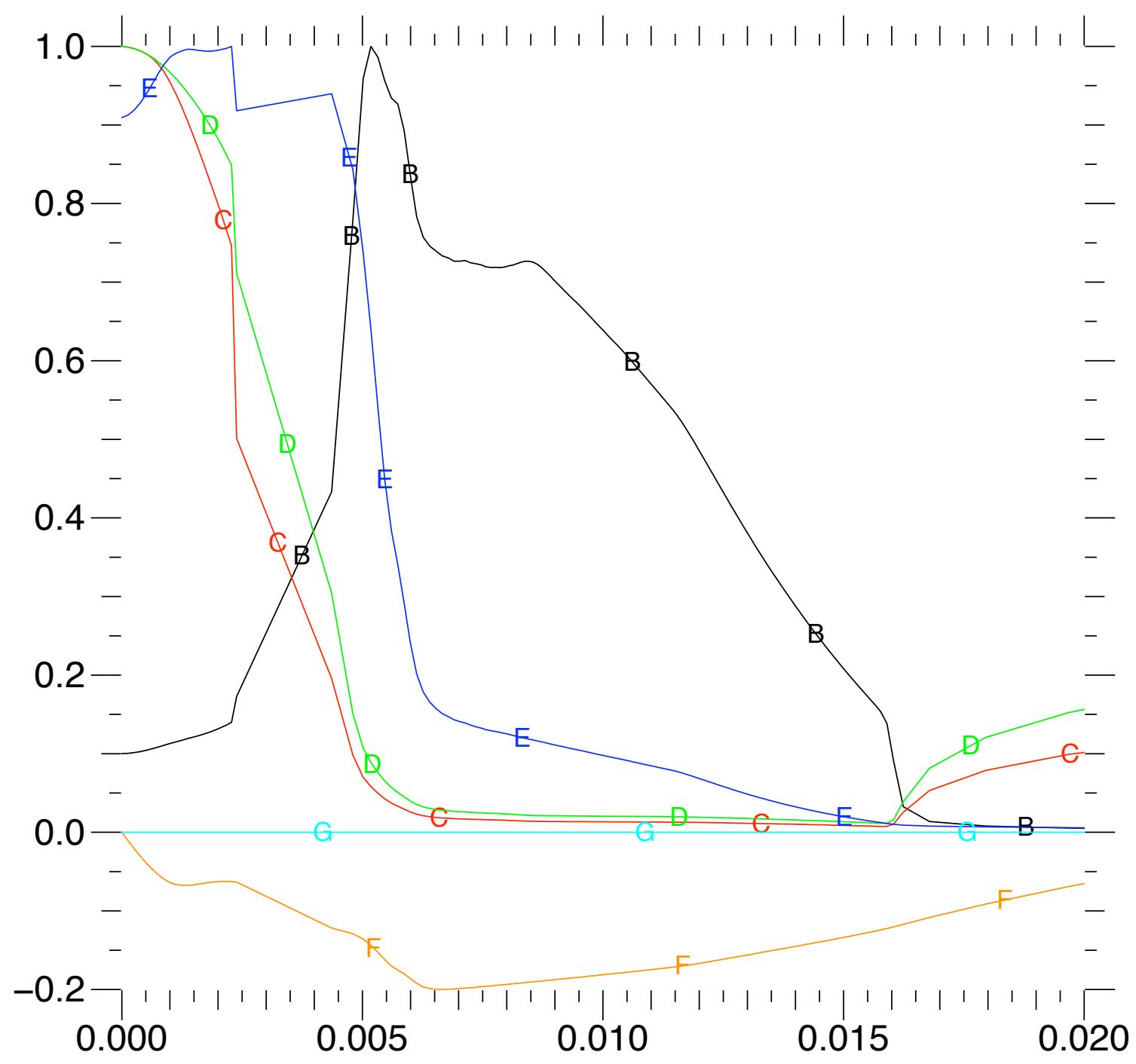

B: $p l g$, density/max(density), $r$

C: plg, ion_temp/max(ion_temp), r

D: plg, electron_temp/max (electron_temp), r

E: plg, pressure/max(pressure), r

F: plg, $-0.2 *$ velocity/min(velocity), r

G: plg, integral_laser_deposition/max(integral_laser_deposition), r

radial slice at max density

max ion temp

8.56000 nanoseconds
$71.5057 \mathrm{~g} / \mathrm{cC}$

max electron temp=

max total pressure =

max inward velocity =

$7743.99 \mathrm{eV}$

$5059.23 \mathrm{eV}$

$38005.3 \mathrm{Mb}$

total laser deposition per unit volume $* d V=$ 
filename $=\mathrm{ftst}$

creation date $=2007-10-1014: 26: 11$

print date $=$ Fri Dec 7 07:49:09 2007

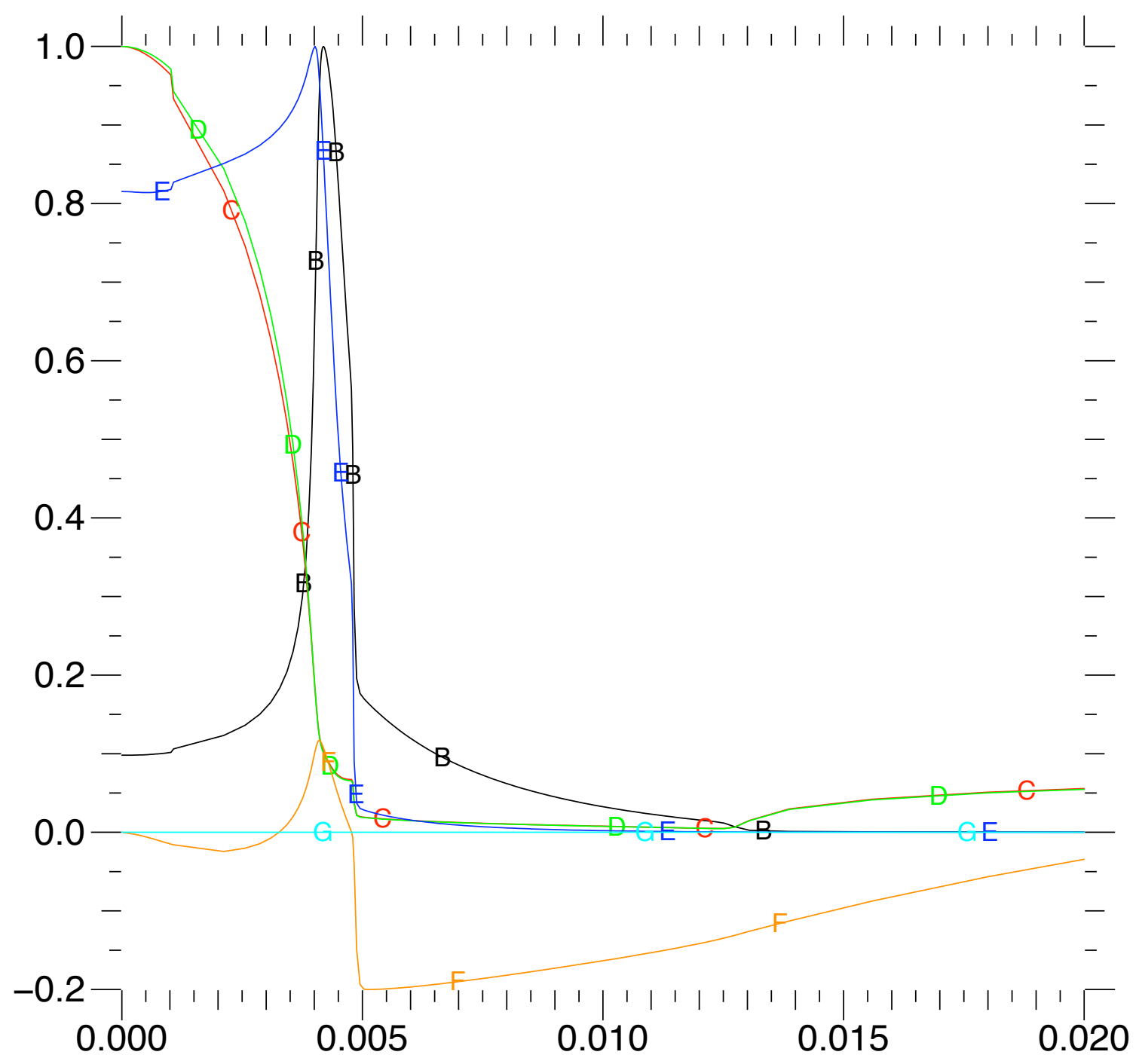

B: $p l g$, density/max(density), $r$

C: plg, ion_temp/max(ion_temp), r

D: plg, electron_temp/max (electron_temp), r

E: plg, pressure $/ \max ($ pressure), r

F: plg, $-0.2 *$ velocity/min(velocity), r

G: plg, integral_laser_deposition/max(integral_laser_deposition), r

radial slice at max density

max ion temp

8.69000 nanoseconds
$923.143 \mathrm{~g} / \mathrm{cC}$

$\max$ electron temp=

max total pressure =

max inward velocity $=$

$=\quad 13547.3 \mathrm{eV}$

$=13838.1 \mathrm{eV}$

total laser deposition

$1.14796 \mathrm{e}+06 \mathrm{Mb}$

$-3.54046 \mathrm{e}+07 \mathrm{~cm} / \mathrm{sec}$

per unit volume * dV $=7.85319 \mathrm{e}-32 \mathrm{TW}$ 